\title{
CORRIGENDUM
}

\section{Effects of schema group therapy in older outpatients: a proof of concept study - CORRIGENDUM}

\author{
A. C. Videler, G. Rossi, M. Schoevaars, C.M. van der Feltz-Cornelis \\ and S. P. J. van Alphen
}

http://dx.doi.org/10.1017/S1041610214001264 Published by Cambridge University Press, 3 July 2014.

In the recent publication (Videler et al., 2014), the name of one of the authors was stated incorrectly. Instead of C. van der Feltz, it should read C.M. van der Feltz-Cornelis, both in the title and in the description of authors' roles.

This error has now been rectified in the original article.

\section{Reference}

Videler, A.C., Rossi, G., Schoevaars, M., Van der Feltz-Cornelis, C.M. and Van Alphen, S.P.J. (2014). Effects of schema group therapy in older outpatients: a proof of concept study. International Psychogeriatrics.

http://dx.doi.org/10.1017/S1041610214001264 